further heterocyst development is acquired before proheterocysts can fix nitrogen, the authors suggest that proheterocysts might be able to transport $\mathrm{NH}_{4}{ }^{+}$to their neighbours. They also point out that heterocysts must become refractory to repression as they continue to synthesise the structural proteins of nitrogenase while fixing nitrogen. Although there are many ways in which induction and repression might be mediated, it is interesting that both groups working on this problem have been forced to models with very similar qualitative features.

The blue-green algae proved a very simple system for the study of pattenned differentiation. It should be possible not only to discover the mechanism for the control of differentiation, but also to correlate differentiation with events at the molecular level, a normally elusive ideal for developmental biologists. Anabaena and Nostoc thus join Hydra and Dictyostelium discoideum as model organisms in which the outlines of a developmental control system are known, and which are simple enough that the details of differentiation during pattern formation can be followed.

From a Correspondent

\section{A Chinese view of tectonics}

Professor J. S. LeE was a Chinese earth scientist highly regarded both in China and the West, so the appearance of a long posthumous article by him entitled "Crustal Structure and Crustal Movement" in Scientia Sinica (16, 519-559; 1973 ) is an event of great interest. The paper was written in 1970, and so cannot claim to be an ideal representation of present-day Chinese thinking on the subject, but it is nevertheless a most fascinating insight into Chinese approaches to tectonics; the more so because Lee's conclusions, based primarily on Chinese evidence, are simultaneously near to and far from Western views.

In a subject as explosively developing as the earth sciences, it is desirable to know how much of the literature of other than Chinese origin the author has consulted. It is clear even in this reference-free paper that Professor Lee had access to nothing beyond about 1963. The magnetic stripes off western North America are described in some detail, but what they imply "is not yet clearly known" beyond that basic or ultrabasic rocks are present. Mid-ocean ridge magnetic anomalies are not mentioned. Seismicity only receives the briefest qualitative attention. With this crippling lack of the ingredients that went into plate tectonics (and without the 1961 seafloor spreading hypothesis), Lee's synthesis is bound to be incomplete. He further complains that "reactionary imperialistic blocs" in scrambling for the wealth of the sea floor and other purposes have not published most of their data. Nevertheless his paper has much interest.

He first looks at the various hypotheses of crustal movement. Some geologists-most of the "traditionalist Americans and some orthodox geotectonicists in the Soviet Union" (Beloussov, no doubt)-insist that vertical movement is dominant and flatly deny the importance of horizontal movement. This he sees as founded in ideas of continental fixation and thus "metaphysical, and utterly dogmatic. This guiding thought was propagated to our land and has brought considerable loss to our geological cause". Lee then goes on to consider possible aspects of crustal movement-cooling and contraction, tides, expansion, convection currents (not ruled out but a "purely metaphysical hypothesis"), isostatic compensation, continental drift and what is called "China's own road". Most of these are dismissed peremptorily, but continental drift (separate from convection currents) is considered briefly as "not entirely unreasonable". Lee, however, cares little for palaeomagnetism and does not accept field reversals.
China's "own road" is an approach which he, as author of a textbook on the geology of China, finds most appealing: learn what you can from China's "extremely superior conditions of structural development". Extensive field work is necessary on structural theories - as Chairman Mao has it, "Man's knowledge is verified only when he achieves the anticipated results": advice perhaps more suited to debugging computer programs than scientific research. Once Lee discovered certain broad scale structural regularities in China, he was prepared to extend them to the rest of the Earth. These features are:

- A latitudinal system of E-W zones revealed by both topography and aeromagnetics. One is at $40^{\circ}$ to $42^{\circ} \mathrm{N}$ and is seen to extend through Central Asia, Turkey, the Mediterranean, under the Atlantic, intersecting the Appalachians, producing an east-west gravity anomaly in the western United States and running into the Mendocino fracture zone. Other world circling zones at $32^{\circ}-34^{\circ} \mathrm{N}$ and $25^{\circ} \mathrm{N}$ are described and one or two in southern latitudes.

- A meridional system is identified by north-south trends, less obvious in China but strong elsewhere such as in the Urals and East Africa.

- The Neocathaysian system striking NNE-SSW is a feature of importance on the oceanic margins of Asia.

- The Cathaysian (NE-SW) system is again an Asiatic feature.

- Shear structural systems are complex but all reflect areas in which there has been shear in the horizontal plane.

Lee observes that surface features are often not in complete agreement with those at greater depth, "in other words they are detached from each other". Furthermore the upper part of continents is inconsistent with the ocean floor and so he is led to consider the importance of horizontal movement. But of what? Earthquakes in Yunnan and Kweichow are about $10 \mathrm{~km}$ deep so it seems that there is a gliding of the upper crust over the lower. North and South America have glided westward from Europe and Africa leaving the Atlantic exposed. In the Pacific it is the ocean floor which is moving westward and the inclined plane of earthquakes beneath Japan and the Kuriles is a manifestation of shearing between the old Pacific and the underside of Asia. Many other instances are given of meridional and latitudinal displacements of the Earth's crust, leading respectively to movement from higher to lower latitudes and to splitting of continents.

What is the driving force? Lee sees forces from the Earth's rotation as the only ones able to produce the two orthogonal types of motion. The resolved tangential component of centrifugal force is seen as the source of movement towards the equator, presumably (though this is not stated) in the form of Polfluchtkraft, the force on floating bodies that so occupied German geodynamicists in the 1920 s. Westward movement is seen, on the other hand, as the result of variations in the rate of rotation of the Earth.

Very little of all this will move Western geophysicists, utterly committed to plate tectonics, to turn with enthusiasm to the Chinese literature. Lee's view of the world, so heavily dominated by what he saw in the field in China, is reminiscent of other qualitative syntheses that were made in the $1960 \mathrm{~s}$, all of which are now forgotten. And yet there is much to learn from this paper. Lee had to develop his ideas in the context of continental tectonics, a field which is still open to much discussion. The paper shows the fierce independence of the Chinese from the influence of the Russian school whose insistence on the dominance of vertical movement in the crust effectively kept the Soviet Union from participating in the excitement of the past ten years. It further shows that although Lee's views were by no means those of the West, there are grounds for discussion with Chinese earth scientists. Students brought up on Lee's interpretations would not find it difficult to understand. if not to accept, plate tectonics.

D. D. 